\title{
Metaphor and Symbol
}

\section{Are Hybrid Pictorial Metaphors Perceived More Strongly Than Pictorial Similes?}

\section{Amitash Ojha, Elisabetta Gola \& Bipin Indurkhya}

To cite this article: Amitash Ojha, Elisabetta Gola \& Bipin Indurkhya (2018) Are Hybrid Pictorial Metaphors Perceived More Strongly Than Pictorial Similes?, Metaphor and Symbol, 33:4, 253-266

To link to this article: https://doi.org/10.1080/10926488.2018.1549837

曲 Published online: 11 Feb 2019.

Submit your article to this journal $₫$

View Crossmark data 


\title{
Are Hybrid Pictorial Metaphors Perceived More Strongly Than Pictorial Similes?
}

\author{
Amitash Ojha $\mathbb{B}^{a}$, Elisabetta Gola $\mathbb{B}^{\mathrm{a}}{ }^{\mathrm{a}}$, and Bipin Indurkhya ${ }^{\mathrm{b}}$ \\ aUniversity of Cagliari; bJagiellonian University
}

\begin{abstract}
The present study examines the relationship between pictorial similes and hybrid pictorial metaphors. The results suggest that hybrid pictorial metaphors are perceived more strongly than pictorial similes when they are presented on their own and in corrective convention but not when they are verbalized. We argue that hybrid pictorial metaphors have transformational effects as the fusion of two concepts allow the reader to see one thing in terms of another. Juxtaposition in a pictorial simile merely suggests a search for similarity, which is not explicit. Results also showed that verbalized metaphor ( $\mathrm{X}$ is $\mathrm{Y}$ ) or the simile ( $\mathrm{X}$ is like $\mathrm{Y}$ ) forms are often used to convey a similar meaning and strength for pictorial simile and pictorial metaphor. However, in corrective scenarios participants are forced to reassess visual features: in this situation, pictorial metaphors are considered more strongly than pictorial similes even when they are verbalized.
\end{abstract}

\section{Introduction}

In literary theory, similes and metaphors are considered to be two different tropes. According to Richards (1936), in metaphors (The man is a wolf) the target (the man) belongs in the category named by the source (a wolf). Similes (The man is like a wolf), on the other hand, asserts a similarity between the target and the source. However, there has been much debate on the relationship between similes and metaphors. For example, the comparison theory of metaphor holds that the differences between these two figures of speech are only superficial and metaphors are actually abbreviated similes, with the terms of comparison left implicit (Billow, 1977; Fogelin, 1988; Fraser, 1979; Gentner, 1989; Gentner \& Clement, 1988; Ortony, 1979b; Tversky, 1977). Miller (1979b) argued that "reconstruction of the implied comparison is a critical step in understanding of metaphor” (p. 228). Chiappe and Kennedy (Chiappe, 1998; Kennedy \& Chiappe, 1999) claimed that metaphor comprehension, like simile comprehension, involves finding relevant common properties of the target and the source, suggesting that they are similar in terms of their processing.

In this regard, several researchers have argued that although they appear to be similar, the metaphors make stronger claims than similes (Black, 1979; Glucksberg \& Keysar, 1990, 1993; Morgan, 1979; Roberts \& Kreuz, 1994). Glucksberg and Keysar (1993) argued, "though many metaphors can be paraphrased as simile, the simile form seems weaker. Similes can always be intensified by putting them in metaphor form" (p. 406). Roberts and Kreuz (1994), based on their experiments, concluded that "a comparison using a simile may be considered less strong than one using a metaphor" (p. 162). Some researchers suggest that metaphors appear to be stronger particularly in "correction convention," which allows speakers uttering similes to be corrected by a corresponding metaphor. For example, if a person says "The man is like a wolf," we can intensify

CONTACT Amitash Ojha amitashojha@gmail.com Department of Pedagogy, Philosophy and Psychology, University of Cagliari, Via Is Mirrionis, Cagliari 09121, Italy

Color versions of one or more of the figures in the article can be found online at www.tandfonline.com/hmet.

(C) 2018 Taylor \& Francis Group, LLC 
the claim by saying "I think the man is a wolf." Similarly, Black (1979), considering the correction convention as a justification, argued, "every metaphorical statement may be said to implicate a likeness-statement ... each weaker than the original metaphorical statement" (p. 31). Verbrugge (1980) claimed that metaphors make the strongest request for a transformation of identity and have a more distinct semantic function than similes. Chiappe and Kennedy (2000) tested the strength of similes and metaphors in a series of experiments. They concluded that metaphors appear to be stronger in corrective scenarios but appear similar to similes when they are comprehended on their own.

While much has been discussed about the relationship between similes and metaphors in the verbal domain, their relationship in other modalities, such as pictorial modality, remains unknown. Pictorial similes and pictorial metaphors are visual counterpart of similes and metaphors in which the concepts (the target and the source) are represented in images. For the last few decades, researchers have argued that tropes of language including metaphors and similes can be depicted in pictures as well. For example, Kennedy (1982) presented a list of 16 tropes and discussed how they could be represented in the pictorial modality. Regarding the relationship between similes and metaphors, he maintained that metaphors in pictures should overlap to make the relationship more apparent. Juxtaposing two concepts beside each other indicates only similarity. Thus “... as in language, so in depiction, the distinction between a metaphor and a simile should be maintained" (p. 603). Similarly, following the Conceptual Metaphor Theory of Lakoff and Johnson (1980), which argued that metaphors are conceptual and can be represented in various modalities, Forceville (1994, 1996) categorized pictorial metaphors into four categories: Pictorial or hybrid metaphors, pictorial similes, contextual metaphors, and integrated metaphor. Most importantly, he made a distinction between "pictorial similes" and "hybrid pictorial metaphors." Pictorial similes are those pictures where both the terms are pictorially depicted and juxtaposed in their entirety. Hybrid metaphors, on the other hand, are those images where they are experienced as a unified object or a gestalt but they actually consist of two different parts that are usually considered as belonging to different domains and not as parts of a single whole. Figure 1 shows an example of hybrid pictorial metaphor and Figure 2 shows an example of pictorial simile.

Although available literature suggests a distinction between pictorial similes and pictorial metaphors on the basis of representation, their relationship has never been tested empirically. Moreover,

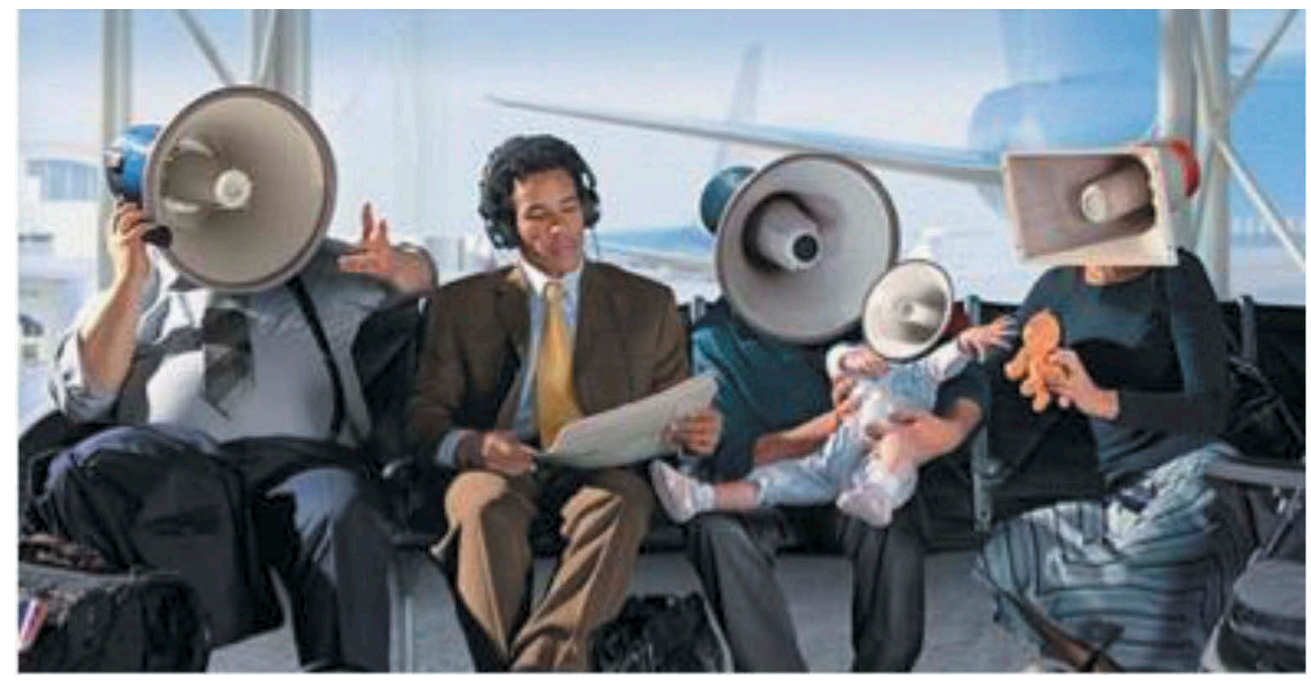

Figure 1. A hybrid pictorial metaphor.

Source: http://adsoftheworld.com 


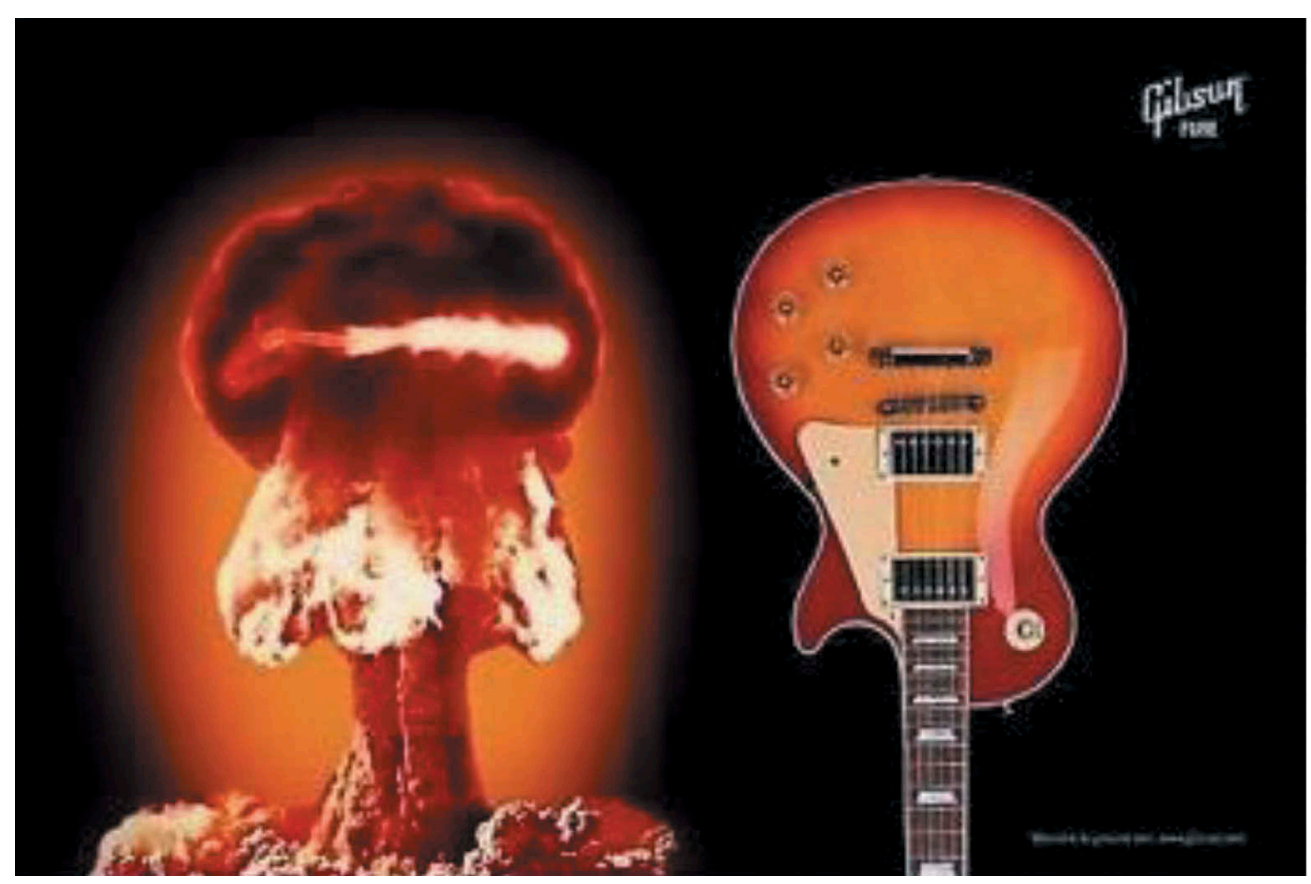

Figure 2. A pictorial simile.

Source: http://adsoftheworld.com

several studies on multimodal metaphors seem to consider both juxtaposition (pictorial simile) and fusion (hybrid metaphor) as kinds of metaphors (Forceville, 2006; Schilperoord, Maes, \& Ferdinandusse, 2009) and do not particularly distinguish them, especially when they are verbalized either in the metaphor form ( $\mathrm{X}$ is $\mathrm{Y}$ ) or in the simile form (X is like $\mathrm{Y}$ ). In our previous studies (Indurkhya \& Ojha, 2013, 2017), we assumed juxtaposition and fusion as creative tools to represent concepts in pictorial modality that invite readers to interpret them metaphorically. However, other researchers have considered fusion as a necessary condition for pictorial metaphors (Carroll, 1994; Kennedy, 1982). Carroll, in particular, argued for the fusion of two concepts, which he calls homspatiality, as a necessary condition for visual metaphors. Given these different approaches in pictorial and multimodal metaphor studies, the relationship between pictorial similes and hybrid metaphors is still not clear. Therefore, the goal of this study is to test the relationship between pictorial similes and hybrid pictorial metaphors. In particular, we would like to investigate empirically if hybrid pictorial metaphors are perceived as stronger than pictorial similes.

\section{Methodology and overview of the experiments}

In this study, perceived strength of pictorial similes and hybrid pictorial metaphors (henceforth pictorial metaphors) were tested in three conditions. In one condition, participants were asked to verbalize pictorial similes and pictorial metaphors either in the metaphor form (X is $\mathrm{Y}$ ) or in the simile form (X is like Y). Forceville $(1996,2002)$ has emphasized the need for verbalization to identify the target and the source and the properties for transfer. In this regard, it may also be noted that many researchers have hinted that metaphorical comprehension is multimodal in nature (Beeman, 2005; Eviatar \& Just, 2006) and comprehension of visual metaphors may require linguistic resources and in some cases, verbalization may be necessary (Forceville, 1996; Ojha, Indurkhya, \& Lee, 2017). In another condition both the pictorial tropes were tested on their own, and the participants were asked not to verbalize them. We assumed that perceived strength of pictorial 
metaphors and pictorial similes may be different when they are not verbalized because processing of pictorial stimuli is fundamentally different from processing of verbal stimuli (Binder et al., 1995; Clark \& Paivio, 1991; Gabrieli et al., 1996; Jonides et al., 1993; Paivio, 1991; Schnotz \& Bannert, 1999). In pictorial stimuli, various perceptual processes play an important role. For instance, explicit surface-level similarities in pictorial metaphor play a significant role in anchoring creative metaphorical interpretations (Indurkhya \& Ojha, 2013). Moreover, studies have produced different results when the visual stimuli are verbalized and when they are not verbalized (Ojha \& Indurkhya, 2016). Finally, the third condition involved corrective convention. Metaphors have been shown to make stronger claims when they are in a corrective convention and when similes are corrected to metaphors (Chiappe \& Kennedy, 2000). Therefore, in this condition, participants were presented with either metaphor corrected by similes or similes corrected by metaphors for each image.

Chiappe and Kennedy (2000) have discussed different indices as measures of strength such as property attribution, attitude of the speaker, and so on. We adapted some of the same measures in our studies and designed few more in different conditions. We provide an overview of the experiments and the tested measures of strength in them. Experiments 1 and 2 tested pictorial similes and pictorial metaphors in the condition without verbalization. In Experiment 1, effectiveness of the image to convey the intended message (either juxtaposed or fused) was tested. In Experiment 2, number of properties attributed to the target in a pictorial simile and a pictorial metaphor was considered as the measure of strength. We hypothesized that if pictorial metaphors are perceived strongly than pictorial similes then more properties would be attributed to the target in a pictorial metaphor. Experiments 3 and 4 included verbalization. In Experiment 3, the participants were given verbalizations either in the metaphor form ( $\mathrm{X}$ is $\mathrm{Y}$ ) or in the simile form ( $\mathrm{X}$ is like $\mathrm{Y}$ ), and were asked to rate their appropriateness. In Experiment 4, the participants were provided with a list of properties, and were asked to attribute them to the target of the image given either the metaphor form or the simile form. The last two experiments included corrective conventions, in which dialogues between two imaginary speakers, one correcting the other, either with the metaphor form or with the simile form, were presented with pictorial simile and pictorial metaphor. In Experiment 5, participants were asked to judge which speaker provided the most appropriate verbalization for the given image. They were also asked to rate the attitude of the speaker, which was considered an additional measure of strength. In Experiment 6, one speaker corrected the other either with more or with fewer properties in both the metaphor and the simile forms. Participants were asked to consider the dialogue and decide with whom they agreed more for the given image (pictorial simile or pictorial metaphor).

\section{Experimental setup}

\section{Pretests}

Prior to the actual experiments, all the participants were tested for their knowledge of English using the Test Of English for International Communication (TOEIC; https://www.ets.org/toeic). All of them were also tested for their creativity using Torrance Tests of Creative Thinking.

\section{Stimulus material preparation}

A set of 11 participants, all from the psychology department, Kyungpook National University, Korea, went through the pictorial similes and pictorial metaphors. All these pictures were print advertisements taken from a website (adsoftheworld.com). Pictorial similes were juxtaposed concepts in a single frame (Figure 2) and pictorial metaphors were images in which two concepts were fused together (Figure 2). No image had any linguistic anchor (in some cases they were manually removed without compromising the meaning). Participants in the pretest were asked to (1) rate the understandability of the image (2) provide verbalization for these images either in the metaphor form (X is $\mathrm{Y}$ ) or in the simile form ( $\mathrm{X}$ is like $\mathrm{Y}$ ), and (3) generate at least 10 properties that could be attributed 
to the target for the given image. On the basis of participants' agreement, (a) 12 pictorial metaphors and 12 pictorial similes were chosen with highest score of understandibility and (b) a list of 10 properties were created for each image. These properties were used in Experiments 2, 4, and 6. Moreover, all the images were tested for their visual complexity using the method of Mudrik, Lamy, and Deouell (2010). The pretest and actual experiments were conducted on a Windows PC.

\section{Condition 1}

In this condition, the strength of pictorial similes and pictorial metaphors were tested without being verbalized. We assumed that pictorial stimuli are processed differently from verbal stimuli and may have different perception of strength when they are not verbalized.

\section{Experiment 1. Effectiveness of the image}

The goal here was to measure the effectiveness of the image (pictorial similes and pictorial metaphors) in conveying the intended message. Participants were specifically asked to consider the message they thought the image conveyed and judge its effectiveness intuitively.

\section{Method}

\section{Participants}

Thirty-two participants (19 males and 13 females) with a mean age of $21.2(S D=0.6)$ participated in the study. These participants were volunteers from a graduate course on creativity and brain in Kyungpook National University, Korea. All of them had high scores on the TOEIC.

\section{Procedure and stimuli}

Participants were shown 12 pictorial similes and 12 pictorial metaphors randomly. They were asked to (a) suggest what is the intended message of the image and (b) rate the effectiveness of the image in conveying the intended message on the scale of 1-9 (1 being not very effective and 9 being highly effective). They were optionally asked to provide the reason for their decision.

\section{Results and discussion}

We calculated the effectiveness ratings as the measure of strength in this experiment. Results are shown in Table 1. The mean effectiveness rating was $8.3(S D=1.6)$ for pictorial metaphors and $4.7(S D=0.8)$ for pictorial similes. The difference was significant, $t(31)=3.37, p<.001$. This result suggested that pictorial metaphors are perceived as more effective than pictorial similes in conveying the message.

\section{Experiment 2. Attribution of properties}

This experiment was designed to measure the strength of pictorial similes and pictorial metaphors in terms of attribution of properties to the target. We hypothesized that if pictorial metaphors are perceived stronger than pictorial similes, a greater number of properties would be attributed to the targets in pictorial metaphors.

Table 1. Results of Experiments 1 and 2.

\begin{tabular}{|c|c|c|}
\hline & Experiment 1 & Experiment 2 \\
\hline & Mean effectiveness & Mean properties \\
\hline Pictorial simile & $4.7^{* * *}$ & $6.2^{* *}$ \\
\hline Hybrid pictorial metaphor & $8.3^{* * *}$ & $8.5^{* *}$ \\
\hline
\end{tabular}




\section{Method}

\section{Participants}

Twenty-four participants (11 males and 13 females) with a mean age of $20.9(S D=1.1)$ participated in the study. Participants were final year graduate students in the psychology department in Kyungpook National University Korea with high TOEIC scores.

\section{Procedure and stimuli}

Participants were shown 12 pictorial similes and 12 pictorial metaphors randomly. They were first instructed to identify the target and the source in the image. Then they were presented with a list of 10 properties after each image collected in the pretest. Participants were asked to mark those properties they thought could be attributed to the target.

\section{Results and discussion}

The mean number of properties attributed to the target was 6.2 in pictorial similes and 8.5 in pictorial metaphors. The difference in the mean values was significant, $t(23)=2.49, p<.01$. This result shows that the participants attributed a greater number of properties to the target in pictorial metaphors, suggesting a greater perceived strength for them.

\section{Condition 2: Verbalization condition}

In Condition 2, the strength of pictorial similes and pictorial metaphors was tested when they are verbalized. Verbalization is useful to identify the target and the source and several studies have used the verbalization method to study visual metaphors theoretically and experimentally. Therefore, in order to properly understand the relationship between pictorial similes and pictorial metaphors, it is also important to study them in the verbalization condition.

\section{Experiment 3(a): Open verbalization}

This experiment explored how participants verbalize pictorial similes or pictorial metaphors. We encouraged participants to identify the target and the source in the image and verbalize them in either the metaphor form ( $\mathrm{X}$ is $\mathrm{Y}$ ) or in the simile form ( $\mathrm{X}$ is like $\mathrm{Y}$ ).

\section{Participants}

Eighteen participants (10 males and 8 females) with a mean age of $22.1(S D=0.9)$ participated in the study. They were volunteers from the psychology department of Kyungpook National University, Korea with high TOEIC scores.

\section{Procedure and stimuli}

Participants were shown 12 pictorial similes and 12 hybrid pictorial metaphors randomly. They were asked to verbalize the image in either the metaphor form " $\mathrm{X}$ is $\mathrm{Y}$ " ( $\mathrm{X}$ being the target and $\mathrm{Y}$ being the source) or in the simile form " $\mathrm{X}$ is like $\mathrm{Y}$." They were also allowed to answer "none" if they were not able to come up with a suitable verbalization.

\section{Results and discussion}

Results are shown in Table 2. A total of $44 \%$ of pictorial similes were verbalized in the metaphor form " $\mathrm{X}$ is $\mathrm{Y}$ " and $46 \%$ were verbalized in the simile form " $\mathrm{X}$ is like $\mathrm{Y}$." The difference was not significant, $t(17)=1.39, n s$. Similarly, a total of $51 \%$ of hybrid pictorial metaphors were verbalized in the metaphor form " $\mathrm{X}$ is $\mathrm{Y}$ " and $48 \%$ were verbalized in the simile form " $\mathrm{X}$ is like $\mathrm{Y}$." This difference was also not significant, $t(17)=1.46, n s$. The result suggested that metaphor form and simile forms are interchangeably used for pictorial simile and pictorial metaphors to indicate similar meaning. 
Table 2. Results of Experiments 3 and 4.

\begin{tabular}{|c|c|c|c|c|}
\hline & & Experiment 3(a) & Experiment 3(b) & Experiment 4 \\
\hline & & Appropriateness & Appropriateness & Property attribution \\
\hline \multirow[t]{3}{*}{ Pictorial simile } & $X$ is $Y$ & 44 & 54 & $6.4(0.3)$ \\
\hline & $\mathrm{X}$ is like $\mathrm{Y}$ & 46 & 49 & $4.2(1.2)$ \\
\hline & None & 10 & 07 & $1.1(0.9)$ \\
\hline \multirow[t]{3}{*}{ Pictorial metaphor } & $X$ is $Y$ & 51 & 49 & $4.7(1.7)$ \\
\hline & $\mathrm{X}$ is like $\mathrm{Y}$ & 48 & 44 & $5.2(1.3)$ \\
\hline & None & 01 & 07 & $0.6(0.2)$ \\
\hline
\end{tabular}

\section{Experiment 3(b): Appropriateness of verbalization}

This experiment was similar to the previous experiment, except that the participants were provided with two verbalizations for each image: one in the metaphor form (X is $\mathrm{Y}$ ) and one in the simile form (X is like $\mathrm{Y}$ ). The participants were asked to judge which of the two verbalizations they thought is the most appropriate for the given image.

\section{Participants}

Sixteen participants ( 9 males and 7 females) with a mean age of $21.2(S D=1.8)$ participated in the study. They were final year students from the psychology department of Kyungpook National University, Korea with high TOEIC scores.

\section{Procedure and stimuli}

Participants were shown 12 pictorial similes and 12 hybrid pictorial metaphors randomly. They were asked to choose the most appropriate verbalization for the shown image from the following three options: (a) metaphor form "X is Y," (b) simile form "X is like $\mathrm{Y}$," and (c) None. These options were presented after each image. They were optionally asked to report if both forms indicated similar meaning for the given image.

\section{Results and discussion}

Results, shown in Table 2, are similar to those of Experiment 3(a). The metaphor form was chosen $54 \%$ of the time as verbalization for pictorial similes and $49 \%$ of the time for pictorial metaphors. The difference was statistically not significant $t(15)=1.55, n s$. Similarly, $49 \%$ of the simile form ( $\mathrm{X}$ is like $\mathrm{Y}$ ) was considered a more appropriate verbalization for pictorial similes and $44 \%$ for pictorial metaphors. This difference was also statistically not significant $t(15)=1.42$, ns. Moreover, $75 \%$ of the participants agreed that both the forms conveyed a similar meaning; only $12.5 \%$ of the participants thought they conveyed different meanings. The rest of them were not sure and did not respond to this question. The results suggest that participants tend to interchange the metaphor and the simile forms for both pictorial similes and pictorial metaphors to indicate similar meaning.

\section{Experiment 4: Property attribution}

Experiment 4 measured the number of property attributions to the target given a metaphor form or a simile form for pictorial similes and pictorial metaphors. Considering a previous study (Chiappe \& Kennedy, 2000), we hypothesized that pictorial metaphors will be seen as attributing more properties to the target. 


\section{Method}

\section{Participants}

Sixteen participants (9 males and 7 females) with a mean age of $21(S D=1)$ participated in the study. All of them were final year graduate students of Kyungpook National University, Korea with high TOEIC scores.

\section{Procedure and stimuli}

Participants were shown 12 pictorial similes and 12 hybrid pictorial metaphors randomly. Each image accompanied a verbalization either in the metaphor form " $\mathrm{X}$ is $\mathrm{Y}$ " or the simile form " $\mathrm{X}$ is like Y." Eight participants were shown six pictorial similes with the metaphor form " $\mathrm{X}$ is $\mathrm{Y}$ " and six pictorial metaphors with the simile form " $\mathrm{X}$ is like $\mathrm{Y}$." The remaining participants were presented with the stimuli in the reverse order. They were also presented with a list of 10 properties for each image collected from the pretest. They were asked to verbalize the image and mark those properties that they thought could be attributed to the target. They were also asked to indicate if both forms indicate a similar meaning for the given image.

\section{Results and discussion}

Results are shown in Table 2. A mean of $6.4(S D=0.3)$ properties were attributed to pictorial similes with the metaphor form " $\mathrm{X}$ is $\mathrm{Y}$ " and a mean of $4.2(S D=1.2)$ properties were attributed with the simile form " $\mathrm{X}$ is like $\mathrm{Y}$." This difference was not significant $t(15)=1.5$, ns. A mean of $4.7(S D=1.7)$ properties were attributed to pictorial metaphors with the metaphor form " $\mathrm{X}$ is $\mathrm{Y}$ " and a mean of 5.2 $(S D=1.3)$ properties were attributed with the simile form " $\mathrm{X}$ is like $\mathrm{Y}$." This difference was also not significant $t(15)=1.42$, ns. Results, together with the results of Experiment 3, suggest that verbalization has an effect on the perceived strength of pictorial metaphors and similes and they are considered to be similar when they are verbalized. The metaphor and the simile forms are interchangeable to indicate a similar meaning.

\section{Condition 3. Corrective situation}

Researchers have argued that metaphors appear to be stronger in corrective scenarios: that is, when a simile is corrected to the corresponding metaphor (Glucksberg \& Keysar, 1993) it tends to intensify the claim. However, methodologically speaking, a correction scenario is possible only when images are verbalized. Therefore, we tested the strength of pictorial similes and pictorial metaphors in Experiments 5 and 6 in a corrective scenario when they are verbalized either in the metaphor form or the simile form. Corrective scenarios were comprised of imaginary dialogues between two speakers, where one speaker corrected a simile form ( $\mathrm{X}$ is like $\mathrm{Y}$ ) to the metaphor form ( $\mathrm{X}$ is $\mathrm{Y}$ ), or a metaphor form with the simile form, for a given image, which was either a pictorial simile or a hybrid pictorial metaphor.

\section{Experiment 5. Appropriateness of the claim and attitude of the speaker}

In this experiment we measured (a) the appropriateness of the claim made by a speaker either in the metaphor form or the simile form for pictorial similes and pictorial metaphors as compared to another speaker and (b) attitude of the speakers. Researchers have suggested that the figure of speech can serve to indicate a speaker's attitude (Bernsten \& Kennedy, 1994, 1996; Fogelin, 1988; Gibbs \& Gerrig, 1989). In a corrective context, a difference in attitude is the focus of attention. Correcting one trope with another is a way of drawing attention to the speaker's attitude. It also suggests that different speakers may feel differently about the target of the trope. For example, in a simile corrected by the metaphor scenario, one speaker verbalizes a pictorial metaphor (Figure 1) as "people's heads are like loudspeakers" and the other speaker corrects the first speaker, saying, "I think their heads are loudspeakers." 


\section{Method}

\section{Participants}

Twenty-eight participants (16 males and 12 females) with a mean age of $21.2(S D=0.8)$ participated in the study. All the participants were final year graduates from Kyungpook National University, Korea with high TOEIC scores.

\section{Procedure and stimuli}

Participants were shown 12 pictorial similes and 12 hybrid pictorial metaphors randomly. Each image accompanied a dialogue between two imaginary speakers, where a metaphor form ( $\mathrm{X}$ is $\mathrm{Y}$ ) corrected to a simile form (X is like $\mathrm{Y}$ ), or vice versa. Fourteen participants were shown "a metaphor form then the corresponding simile form" and then "a simile form then the corresponding metaphor form." The remaining 14 participants were shown the same stimuli in the reverse order. The participants were asked to judge which speaker (a) had the most appropriate verbalization for the given image (speaker A, B, or none) and (b) rate one of the two speakers who they thought expressed greater attitude toward the target on a scale of 1-9 (1 being too weak and 9 being much stronger).

\section{Results and discussion}

Table 3 shows the results of the experiment. For pictorial similes, when the metaphor form corrected the simile form, the mean appropriate rating was $5.9(S D=0.6)$ and when the simile form corrected the metaphor form, the appropriateness rating was $3.6(S D=0.3)$. The difference was significant, $t(27)=3.47 . p<.001$. For pictorial metaphor when the metaphor form corrected the simile form, the mean appropriateness rating was $7.3(S D=1.2)$ and when simile form corrected metaphor, the mean appropriateness rating was $2.6(S D=1.8)$. The difference was also statistically significant, $t(27)=3.71 . p<.001$. Similarly, for pictorial similes, when the metaphor form corrected the simile form, the mean attitude rating was $6.6(S D=0.5)$ and when the simile form corrected the metaphor form, the mean attitude rating was $5.1(S D=0.3)$. The difference was significant, $t(27)=3.42$. $p<.001$. For pictorial metaphor when the metaphor form corrected the simile form, the mean attitude rating was $6.2(0.7)$ and when simile form corrected metaphor, the mean attitude rating was $3.4(S D=0.5)$. The difference was also statistically significant, $t(27)=2.95 . p<.01$. These results suggested that participants tend to give higher appropriateness rating for images when a simile form is corrected to the metaphor form. Similarly, the attitude of the speaker who corrects simile forms to metaphor forms is perceived as stronger.

\section{Experiment 6: Property attribution}

This experiment also included correction but in a different way. A pictorial simile or a pictorial metaphor accompanied a dialogue in which a verbalized simile form or a metaphor form was corrected by a simile form or a metaphor form with either fewer (two) properties or more (five) properties. Participants were asked "how much they agreed with the correcting speaker?" For example, verbalizing a pictorial simile in a simile form with fewer properties ("cigarettes are killers

Table 3. Results of Experiment 5.

\begin{tabular}{llcc}
\hline & \multicolumn{1}{c}{ Experiment 5} \\
\hline Pictorial simile & \multicolumn{1}{c}{ Dialogue } & Mean appropriateness rating & Mean attitude rating \\
\hline & Simile form corrected to Metaphor form & $5.9(0.6)^{* * *}$ & $6.6(0.5)^{* * *}$ \\
& Metaphor form corrected to Simile form & $3.6(0.3)^{* * *}$ & $5.1(0.3)^{* * *}$ \\
& None & $0.6(0.4)$ & $1.2(0.2)$ \\
& Sictorial metaphor & $7.3(1.2)^{* * *}$ & $6.2(0.7)^{* *}$ \\
& Metaphor form corrected to Simile form & $2.691 .8)^{* * *}$ & $3.4(0.5)^{* *}$ \\
& None & $0.4(0.5)$ & $0.8(0.2)$ \\
\hline
\end{tabular}

${ }^{* *} p<.01,{ }^{* * *} p<.001$ 
and dangerous like bullets") was corrected by another speaker who verbalized the same pictorial simile in a metaphor form with more properties ("Well I think, cigarettes are killing, dangerous, painful, fast and powerful bullets").

\section{Method}

\section{Participants}

Thirty-two participants (16 males and 16 females) with a mean age of $21.2(S D=0.8)$ participated in the study. All the participants were final year graduates from Kyungpook National University, Korea with high TOEIC scores.

\section{Procedure and stimuli}

Participants were shown 12 pictorial similes and 12 hybrid pictorial metaphors. Each image accompanied a dialogue in which one speaker attributed certain number of properties (two to five) to the target and the other corrected him/her by attributing more (up to five) properties or fewer (two) properties for both metaphor form ( $\mathrm{X}$ is $\mathrm{Y}$ ) and simile form ( $\mathrm{X}$ is like $\mathrm{Y}$ ). There were six conditions in which corrections were tested. In the first condition, a simile form was corrected to the same simile form but with more properties $(S \rightarrow S(+))$. In the second condition, a simile form was corrected to the same simile form but with fewer properties $(S \rightarrow S(-))$. In the third condition, a simile form was corrected to a metaphor form with more properties $(S \rightarrow M$ $(+)$ ). In the fourth condition, a simile form was corrected to a metaphor form with fewer properties $(S \rightarrow M(-))$. In the fifth condition, a metaphor form was corrected to a metaphor form with fewer properties $(\mathrm{M} \rightarrow \mathrm{M}(-))$, and finally in the sixth condition, a metaphor form was corrected to the same metaphor form but with more properties $(M \rightarrow M(+))$. An equal number of conditions were shown to the participants. They were asked to consider the given dialogue and rate with which they agreed with the correcting speaker for the given image on a scale of 1-9 (1 being the strongly disagree and 9 being strongly agree).

\section{Results and discussion}

Results are shown in Table 4. The agreement rating for pictorial metaphor was significantly higher than the agreement rating for pictorial simile in $\mathrm{S} \rightarrow \mathrm{S}(+), t(31)=1.69, p<.05, \mathrm{~S} \rightarrow \mathrm{M}$ $(+), t(31)=2.45, p<.01$ and $\mathrm{M} \rightarrow \mathrm{M}(+), t(31)=2.56, p<.01$ conditions. In $\mathrm{S} \rightarrow \mathrm{S}(-)$, $t(31)=1.32$, $n s$ and $\mathrm{M} \rightarrow \mathrm{M}(-), t(31)=1.51, p<n s$ showed the difference was insignificant. During the $\mathrm{S} \rightarrow \mathrm{M}(-)$ condition, the difference was very low, but it was not found to be statistically significant, $t(31)=1.12$, ns. Overall, results of this experiment showed that participants are more likely to associate more properties to pictorial metaphor than pictorial simile.

Table 4. Results of Experiment 6.

\begin{tabular}{lcc}
\hline \multicolumn{3}{c}{ Experiment 6} \\
\hline Conditions & Agreement ratings for pictorial simile & Agreement ratings for pictorial metaphor \\
\hline$S \rightarrow S(+)$ & $3.9(1.1)^{*}$ & $6.5(.04)^{*}$ \\
$S \rightarrow S(-)$ & $4.4(0.7)$ & $5.2(0.4)$ \\
$S \rightarrow M(+)$ & $4.2(0.9)^{* *}$ & $7.4(0.6)^{* *}$ \\
$S \rightarrow M(-)$ & $5.4(1.7)$ & $6.6(1.3)$ \\
$M \rightarrow M(+)$ & $6.1(0.4)^{* *}$ & $7.5(0.2)^{* *}$ \\
$M \rightarrow M(-)$ & $4.2(1.4)$ & $5.2(0.9)$ \\
\hline
\end{tabular}

${ }^{*} \mathrm{p}<.05,{ }^{* *} \mathrm{p}<.01,{ }^{* * *} \mathrm{p}<.001$ 


\section{General discussion}

The goal of this study was to examine the relationship between pictorial similes and pictorial metaphors in three different conditions. In particular, our aim was to determine if pictorial metaphors are perceived stronger than pictorial similes. Our results provided mixed results in different conditions. Below we discuss the implications of the results.

The results of Experiments 1 and 2 in the first condition, in which the participants did not verbalize the pictorial stimuli, suggested that pictorial metaphors are perceived as more effective and stronger than pictorial similes in conveying the message. In particular, the results of Experiment 2 showed that participants attribute a greater number of properties to the target in pictorial metaphors than in pictorial similes. This difference in perceived strength could be due to different reasons. First, the representation style. Pictorial similes represent two distinct concepts in a single frame. There is no clue other than the juxtaposition of two concepts, which suggests a metaphorical relation between them (unless explicitly provided by text or context). Pictorial metaphors, on the other hand, explicitly fuse two concepts, suggesting a metaphorical relationship and highlighting properties that could be attributed to the target. The fusion of two concepts seems to be more assertive than the juxtaposition.

Second, the metaphorical comprehension requires a viewer to see one concept in terms of another. The fusion of two concepts into a whole in a pictorial metaphor has a transformational effect, which explicitly allows the viewer to see a physical possibility in which two concepts from different domains could be perceived as similar or identical. Juxtaposition, on the other hand, leaves this important aspect of seeing to the subjective imagination of the viewer. Nevertheless, we have argued earlier that perceptual similarity between two concepts, when they are juxtaposed, could help to see the metaphorical relationship by facilitating the process of identification, initially at the surface level, and then later at a higher conceptual level (Indurkhya \& Ojha, 2013; Ojha \& Indurkhya, 2016). However, the perceptual similarity between two concepts in a juxtaposition scenario remains only a suggestion to compare two concepts and interpret them figuratively. Explicit fusion of two concepts is more explicit in terms of directing the viewer's thoughts toward a transformation and allowing her or him to better see one concept in terms of another.

Verbrugge (1980) has discussed the role of transformational effect on the relationship between similes and metaphors. In an experiment, he asked the participants to read either metaphors or similes, and asked them to describe the images or thoughts that came to mind. The results showed that participants who received metaphors were more likely to produce "transformational responses," which involved fusing the target and the source. For example, participants on reading "skyscrapers are giraffes" reported "I saw large, tall, windowed buildings, which became very skinny and developed spots" (p. 110). Participants who read similes produced a list of common features. Verbrugge (1980) argued that "the metaphor form (rather than the simile) is more likely to catalyse a reader's thought in a transformational direction ... from this perspective ... it is reasonable to argue that the metaphor form does have a distinct semantic function" (pp. 119-120).

However, we found opposite results when pictorial similes and pictorial metaphors were verbalized. Our results suggest that the verbalized metaphor ( $\mathrm{X}$ is $\mathrm{Y}$ ) and the simile (X is like $\mathrm{Y}$ ) forms were used equally and interchangeably for both pictorial similes and pictorial metaphors to suggest similar meaning. It must be noted that verbalization is a higher-level conceptual process acting over a lower-level perceptual process (Humphreys, 2016; Treisman \& Gelade, 1980). Considering our results, we assume that once the pictorial metaphor or pictorial similes are verbalized, the effect of perceptual processing is lost in the higher-level conceptual processes of finding similarities (Indurkhya, Kattalay, Ojha, \& Tandon, 2008; Ojha \& Indurkhya, 2016). That is, the pictorial representation becomes redundant and the metaphor is processed only as a verbal metaphor. Previous research has shown that verbal similes and verbal metaphors are perceived as similar in terms of their strength (Chiappe \& Kennedy, 2000) when they are presented on their own. 
Nonsignificant results in Condition 2 when compared to Condition 1 strongly suggest that verbalized pictorial stimuli are processed as verbal stimuli, leaving out visual features of the depiction.

The result that the metaphor ( $\mathrm{X}$ is $\mathrm{Y}$ ) and simile ( $\mathrm{X}$ is like $\mathrm{Y}$ ) forms are often interchangeable when pictorial stimuli is verbalized, without compromising the meaning, may have an interesting implication for experimental work on visual metaphors. Experimental studies on pictorial metaphors suffer from a methodological problem-even if the input is pictorial, the response of the participants, in most cases, is verbal. Researchers have wondered if the verbalized metaphor and the simile forms activate similar meaning. Our results suggest that the metaphor and the simile forms are perceived similarly when the image is verbalized. In terms of strength, both forms seem to attribute a similar number of properties to the target.

In the correction convention, we found that pictorial metaphors are perceived stronger than pictorial similes even if they are verbalized. In particular, the results of Experiment 6 showed that more participants agree with the speaker who corrected the simile form ( $\mathrm{X}$ is like $\mathrm{Y}$ ) to the metaphor form ( $\mathrm{X}$ is $\mathrm{Y}$ ) with more properties for pictorial metaphors. Interestingly, we also found that the participants tend to associate more properties with pictorial metaphors, even when the simile form was corrected to the simile form but with more properties. We suggest that in a corrective scenario, different processes play important role. The verbalized metaphor and the simile forms, which are often interchanged, are revisited in corrective scenarios and the perceptual and structural properties of images are reassessed. Attribution of more properties forces the participants to revisit the image. Perceptual processing, which is usually lost in the verbal processing, is brought into the forefront when more properties are presented. In this process, the initial impression of fusion plays an important role and is perceived more strongly compared to the situation with juxtaposed images.

The attitude of the speakers in Experiment 5 also indicates the difference in perceived strength of pictorial similes and pictorial metaphors. Our results suggest that the participants favored those speakers who corrected simile forms to metaphor forms for both pictorial similes and pictorial metaphors. Roberts and Kreuz (1994) have argued that metaphors are used to emphasize points in discourse, as compared to similes, which are used to deemphasize points. Many researchers have maintained that figures of speech, especially metaphors, often communicate the speaker's attitude (Gibbs \& Gerrig, 1989). For example, when using a metaphor, the speaker is making a communication point that does not necessarily add to our knowledge of the target, but rather serves as a commentary on the speaker's attitude toward the topic. Furthermore, in corrective contexts, a difference in attitude could be the focus of attention. Correcting one trope with another might be a way of drawing attention to the speaker's attitude, showing that the second speaker feels differently about the target. This attitude, in our case, may correlate with the initial perceptual processing, in which a stronger assertion in the form of the fusion of two concepts is reaffirmed.

\section{Conclusion}

Overall, our studies suggest that pictorial metaphors are perceived more strongly than pictorial similes, especially when they are not verbalized. They are also perceived more strongly in corrective scenarios. However, when they are verbalized, they are likely to be processed as verbal simile and verbal metaphors, and are considered similar in terms of their strength. We argue that the strength of a metaphor comes from the way it is represented in the image. Fusion of two non-similar concepts in a hybrid pictorial metaphor has a transformational effect, which allows the reader to see a concept in terms of another by emphasizing the properties for transfer. A pictorial simile does not assert the identity and merely suggests a similarity, which leaves the search for similar properties to the subjective imagination of the reader. While in corrective situations, the metaphor form for a pictorial metaphor is perceived more strongly than a pictorial simile because perceptual properties, which are usually lost in verbal processing, are reassessed and revisited. 
In this study we only used hybrid pictorial metaphors. However, pictorial metaphors can be represented in other ways too, such as contextual metaphor and integrated metaphors. In future experiments, it would be interesting to compare these other forms with pictorial similes.

\section{Disclosure statement}

No potential conflict of interest was reported by the authors.

\section{ORCID}

Amitash Ojha (D) http://orcid.org/0000-0002-1079-2270

Elisabetta Gola (iD http://orcid.org/0000-0003-0966-9520

\section{References}

Berntsen, D., \& Kennedy, J. M. (1994). Contradictions between metaphors: A means of expressing an attitude. Metaphor and Symbol, 9(3), 193-209. doi:10.1207/s15327868ms0903_3

Berntsen, D., \& Kennedy, J. M. (1996). Unresolved contradictions specifying attitudes-In metaphor, irony, understatement and tautology. Poetics, 24(1), 13-29. doi:10.1016/0304-422X(95)00013-A

Billow, R. M. (1977). Metaphor: A review of the psychological literature. Psychological Bulletin, 84, 81-92. doi:10.1037/ 0033-2909.84.1.81

Binder, J. R., Swanson, S. J., Wagner, A. D., Demb, J. B., Shear, P. K., Glove, G. H., ... Rao, S. M. (1995). Determination of language dominance with functional MRI: A comparison with the Wada test. Human Brain Mapping, 1, 235.

Black, M. (1979). More about metaphor. In A. Ortony (Ed.), Metaphor and thought (pp. 19-43). New York, NY: Cambridge University Press.

Chiappe, D. L. (1998). Similarity, relevance, and the comparison process. Metaphor and Symbol, 13, 17-30. doi:10.1207/s15327868ms1301_2

Chiappe, D. L., \& Kennedy, J. M. (2000). Are metaphors elliptical similes? Journal of Psycholinguistic Research, 29(4), 371-398.

Clark, J. M., \& Paivio, A. (1991). Dual coding theory and education. Educational Psychology Review, 3(3), 149-210. doi:10.1007/BF01320076

Eviatar, Z., \& Just, M. A. (2006). Brain correlates of discourse processing: An fMRI investigation of irony and conventional metaphor comprehension. Neuropsychologia, 44(12), 2348-2359. doi:10.1016/j.neuropsychologia.2006.05.007

Fogelin, R. (1988). Figuratively speaking. New Haven, CT: Yale University Press.

Forceville, C. (1994). Pictorial metaphors in advertisements. Metaphor and Symbolic Activity, 9(1), 1-29. doi:10.1207/ s15327868ms0901_1

Forceville, C. (1996). Pictorial metaphor in advertising. Routledge: London.

Forceville, C. (2002). The identification of target and source in pictorial metaphors. Journal of Pragmatics, 34(1), 1-14. doi:10.1016/S0378-2166(01)00007-8

Forceville, C. (2006). Non-verbal and multimodal metaphor in a cognitivist framework: Agendas for research. Applications of Cognitive Linguistics, 1, 379.

Fraser, B. (1979). The interpretation of novel metaphors. In A. Ortony (Ed.), Metaphor and thought (pp. 172-185). New York, NY: Cambridge University Press.

Gabrieli, J. D., Desmond, J. E., Demb, J. B., Wagner, A. D., Stone, M. V., Vaidya, C. J., \& Glover, G. H. (1996). Functional magnetic resonance imaging of semantic memory processes in the frontal lobes. Psychological Science, 7 (5), 278-283. doi:10.1111/j.1467-9280.1996.tb00374.x

Gentner, D. (1989). The mechanisms of analogical learning. In S. Vosniadou \& A. Ortony (Eds.), Similarity and analogical reasoning (pp. 199-241). Cambridge, MA: Cambridge University Press.

Gentner, D., \& Clement, C. (1988). Evidence for relational selectivity in the interpretation of analogy and metaphor. The Psychology of Learning and Motivation, 22, 307-358.

Gibbs, R. W., Jr, \& Gerrig, R. J. (1989). How context makes metaphor comprehension seem special'. Metaphor and Symbol, 4(3), 145-158. doi:10.1207/s15327868ms0403_3

Glucksberg, S., \& Keysar, B. (1990). Understanding metaphorical comparisons: Beyond similarity. Psychological Review, 97, 3-18. doi:10.1037/0033-295X.97.1.3

Glucksberg, S., \& Keysar, B. (1993). How metaphors work. In A. Ortony (Ed.), Metaphor and thought (2nd ed., pp. 401-424). New York, NY: Cambridge University Press. 
Humphreys, G. W. (2016). Feature confirmation in object perception: Feature integration theory 26 years on from the Treisman Bartlett lecture. The Quarterly Journal of Experimental Psychology, 69(10), 1910-1940. doi:10.1080/ 17470218.2014.988736

Indurkhya, B., Kattalay, K., Ojha, A., \& Tandon, P. (2008). Experiments with a creativity-support system based on perceptual similarity. SoMeT (pp. 316-327).Sharjah, United Arab Emirates.

Indurkhya, B., \& Ojha, A. (2013). An empirical study on the role of perceptual similarity in visual metaphors and creativity. Metaphor and Symbol, 28(4), 233-253. doi:10.1080/10926488.2013.826554

Indurkhya, B., \& Ojha, A. (2017). Interpreting visual metaphors: Asymmetry and reversibility. Poetics Today, 38(1), 93-121. doi:10.1215/03335372-3716240

Jonides, J., Smith, E. E., Poeppe, R. A., Awh, E., Minoshima, S., \& Mintun, M. A. (1993). Spatial working memory in humans as revealed by PET. Nature, 363, 623-625. doi:10.1038/363623a0

Jung-Beeman, M. (2005). Bilateral brain processes for comprehending natural language. Trends in Cognitive Sciences, 9 (11), 512-518. doi:10.1016/j.tics.2005.09.009

Kennedy, J. M. (1982). Metaphor in pictures. Perception, 11(5), 589-605. doi:10.1068/p110589

Kennedy, J. M., \& Chiappe, D. L. (1999). What makes a metaphor stronger than a simile? Metaphor and Symbol, 14, 63-69. doi:10.1207/s15327868ms1401_7

Lakoff, G., \& Johnson, M. (1980). Conceptual metaphor in everyday language. The Journal of Philosophy, 77(8), 453-486. doi:10.2307/2025464

Morgan, J. L. (1979). Observations on the pragmatics of metaphor. In A. Ortony (Ed.), Metaphor and thought (pp. 136-147). New York, NY: Cambridge University Press.

Mudrik, L., Lamy, D., \& Deouell, L. Y. (2010). ERP evidence for context congruity effects during simultaneous objectScene processing. Neuropsychologia, 48(2), 507-517. doi:10.1016/j.neuropsychologia.2009.10.011

Ojha, A., \& Indurkhya, B. (2016). On the role of perceptual features in metaphor comprehension. In: Gola E and Ervas F (eds), Metaphor and communication (pp. 147-170). Amsterdam: John Benjamins.

Ojha, A., Indurkhya, B., \& Lee, M. (2017). Is language necessary to interpret visual metaphors? Metaphor in Communication, Science and Education, 36, 61.

Ortony, A. (1979b). The role of similarity in similes and metaphors. In A. Ortony (Ed.), Metaphor and thought (pp. 186-201). New York, NY: Cambridge University Press.

Paivio, A. (1991). Dual coding theory: Retrospect and current status. Canadian Journal of Psychology, 45(3), $255-287$. doi: $10.1037 / \mathrm{h} 0084295$

Richards, I. A. (1936). The philosophy of rhetoric. New York, NY: Oxford University Press.

Roberts, R. M., \& Kreuz, R. J. (1994). Why do people use figurative language? Psychological Science, 5, $159-163$. doi:10.1111/j.1467-9280.1994.tb00653.x

Schilperoord, J., Maes, A., \& Ferdinandusse, H. (2009). Perceptual and conceptual visual rhetoric: the case of symmetric object alignment. Metaphor and Symbol, 24(3), 155-173. doi:10.1080/10926480903028110

Schnotz, W., \& Bannert, M. (1999, October). Support and interference effects in learning from multiple representations. European conference on cognitive science (pp. 447-452). Rome, Italy.

Treisman, A. M., \& Gelade, G. (1980). A feature-integration theory of attention. Cognitive Psychology, 12(1), 97-136.

Tversky, A. (1977). Features of similarity. Psychological Review, 84, 327-352. doi:10.1037/0033-295X.84.4.327

Verbrugge, R. (1980). Transformations in knowing: A realist view of metaphor. In R. Honeck \& R. Hoffman (Eds.), Cognition and figurative language (pp. 87-125). Hillsdale, NJ: Erlbaum. 